\title{
Acute Calcific Tendinitis of the Subscapularis Tendon: A Rare Case Diagnosed by Ultrasound Imaging and Treated Successfully?
}

\author{
Kübra Neslihan Kurt ${ }^{1}$, Ilknur Aktaş ${ }^{1}$ and Barış Yılmaz ${ }^{2 *}$ \\ ${ }^{1}$ Department of Physical Treatment and Rehabilitation, Turkey \\ ${ }^{2}$ Department of Orthopaedic Surgery and Traumatology, Turkey
}

*Corresponding author: Barış Yilmaz, Department of Orthopedic Surgery, Turkey.

Received Date: September 19, 2018

Published Date: November 16, 2018

\begin{abstract}
Calcific tendinitis is characterised by calcium deposits in the rotator cuff tendon. Most commonly involves the supraspinatus tendon, followed by infraspinatus, teres minor, and rarely in subscapularis. Leading a painful shoulder dysfunction and its exact etiology is still unknown. Depending on the biologic stage of the disease, conservative management (NSAIDs , physiotherapy, ultrasound guided needling, iontophoresis and ESWT) or surgical removing are choosen. We report a 44-year-old man with calcific tendinitis of left subscapularis tendon diagnosed by ultrasound imaging and treated with corticosteroid injection followed by a physical therapy course. He had progressive improvement of pain 2 weeks after injection. At week 6, the patient was pain-free and had partial resolution of calcific tendinitis. He regained full range of motion and resumed all his daily living activities.
\end{abstract}

Keywords: Calcific tendinitis; Calcinosis; Shoulder pain; Shoulder joint; Subscapularis tendon; Tendinopathy

\section{Introduction}

Calcific tendinitis (CT) is an acute or chronic painful shoulder disorder characterised by single or multiple deposits of calcium hydroxyapatite crystals in the rotator cuff tendon or subacromial bursa leading to inflammation around deposits [1-3]. The most commonly affected tendon is the supraspinatus tendon at its insertion on the humerus trochanter , being involved in $51-82 \%$ of cases. More rarely, it is located on the infraspinatus (15-30\%), the subscapularis (10\%), or the teres minor $(<10 \%)$ [1]. Approximately $6.8 \%$ of patients with painful shoulders are caused by CT.

The appearance of the subscapularis Calcific tendinitis is extremely rare and takes place in the literature as case reports. We aimed to present a case of subscapular calcific tendinitis which was diagnosed by shoulder ultrasonography and applied to our clinic with a sudden onset of severe shoulder pain.

\section{Case Presentation}

A 44 year old male who is an orthopedic surgeon admitted to our outpatient clinic with complaint of anterior shoulder pain. He had a history of intense left shoulder (non-dominant shoulder) pain followed by a loss of motion after 48 hours. There were no response to analgesic and coldpack. He had no history of trauma or metabolic disease. Functional ability of the patient was restricted to a larger extent, such that patient had difficulty in surgery, sleep and daily living activities. On physical examination he had no edema, no asymmetria in skin colour and temperature . On palpation, there was marked tenderness over the part of his left shoulder near the tendinous insertion of the subscapularis muscle. Both passive and active movements of his left shoulder were restricted due to the severe pain. Neurological examination were normal. It was diffucukt to perform any of the special tests due to the unbearable pain. Roentgenogram and laboratory investigation were in normal range excluding fracture and infection. Ultrasound guided imaging showed us the hypointense calcification in the area of subscapularis insertion anterior to humeral head close to the lesser tuberosities (Figure 1).

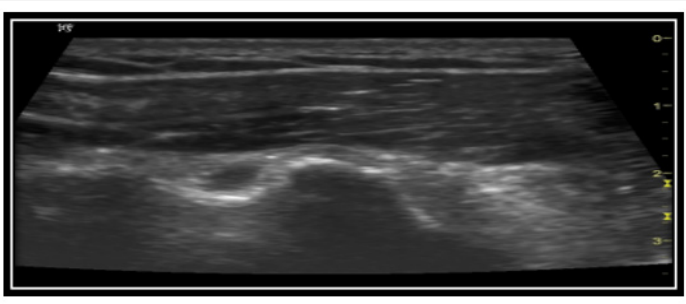

Figure 1: USG imaging of left shoulder showing calcificitation (or calcified deposit) before injection. 


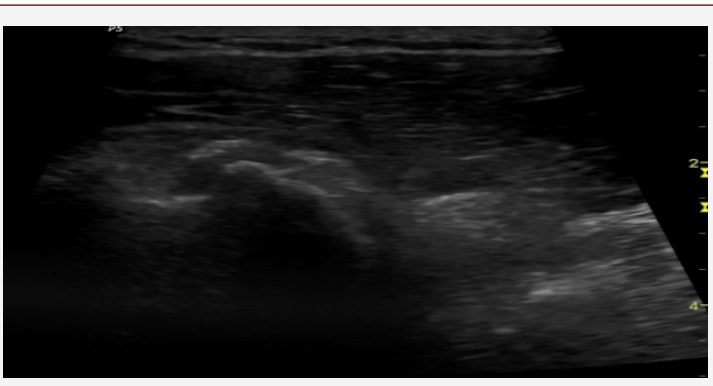

Figure 2: Follow-up imaging.

After patient was diagnosed as subscapularis calcific tendinitis with severe pain and limitation in ROM, corticosteroid injection is planned to gain quick relief in pain and to return to work early. Corticosteroid was injected into the calsification area. After injection, pharmacological treatment (oral NSAID twice daily) and physical therapy \& rehabilitation programme including cold pack, transcutaneous electrical nerve stimulation (TENS) and ultrasound with shoulder ROM, streching \& strengthening exercises were planned for 3 weeks. 2 weeks after injection, patient's NRS (numeric rating scale) score was reduced from $8 / 10$ to $2 / 10$. Substantial improvements in pain and gain in shoulder ROM was achieved at the end of 6 weeks. Repeat USG imaging of his left shoulder showed that the previous calcified lesion had disappeared (Figure 2).

\section{Discussion}

Calcific tendinitis usually appears between ages 40 and 60 [4]. Housewives and people in sedentary occupations are more likely to develop CT. Women are more likely to have CT than males (57-76\%) , and dominant shoulder is affected more frequently [4]. The deposits are seen bilaterally in $10-20 \%$ of patients [2]. Acute pain is often associated with the onset of the disease; however the prevalence of asymptomatic calcifications in the rotator cuff is reported to be between $2.7-20 \%$ [5].

Although the exact cause of CT of the rotator cuff muscles remains unclear, some extrinsic and intrinsic factors related to ageing, vascularity, overloading, endocrinological status, genetics etc. are thought to have contributions in etiopathogenesis [6]. Uhthoff et al. [7], proposed that the calcific tendinitis goes through three stages consisting of precalcific, calcific and postcalcific. In the precalcific stage, fibrocartilaginous metaplasia is seen in the tendon; this stage is rarely symptomatic. This is followed by the calcific stage, which is composed of formative, resting and reabsorption phases. The reabsorptive phase is where the patients are mostly symptomatic. The postcalcific phase is the healing phase, in which reabsorption of the deposit happens. During the acute resorptive phase, patients usually experience intense pain, inflammation, and markedly limited range of shoulder motion.

Although in the majority of cases reabsorption of deposits and complete relief in pain occurs spontaneously, there are several treatment options that depend on the biologic state of the disease $[7,8]$. Firstline conservative therapy includes cold pack, oral analgesics including anti-inflammatory drugs, physiotherapy; minimally invasive techniques include injection of local anaesthetic w/o concomitant steroid infiltration, ultrasound guided needling or puncture and aspiration. If these treatments fail , surgical treatment (arthroscopic or open) is considered. Due to intolerable pain in acute and severely painful resorptive stage, any minimally invasive or operative intervention may be demanded first.

In literature, there are only 2 cases [1,9] reporting subscapularis calcific tendinitis (first one is dominant shoulder, the second one is bilateral shoulder) where conservative treatment (physiotherapy , oral non-steroidal anti-inflammatory drugs, iontophoresis) and also hyaluronic acid injections failed to resolve the symptoms, and sequential arthroscopic debridement of calcific tendinitis of the subscapularis tendons was performed.

Here we represent a case of subscapularis calcific tendinitis of left shoulder which is an rarely seen localization of rotator cuff tendinopathies and responded dramatically to the USG guided injection of corticosteroid and physiotherapy course. The aim of this report is to increase the general awareness of the atypical localization of rotator cuff tendinopathies and importance of ultrasound imaging in early diagnose and early treatment.

\section{Acknowledgement}

None.

\section{Conflict of Interest}

No conflicts of interest.

\section{References}

1. Vinanti GB, Pavan D, Rossato A, Carlo Biz (2015) Atypical localizations of calcific deposits in the shoulder. Int J Surg Case Rep 10: 206-210.

2. Merolla G, Singh S, Paladini P, Porcellini G (2016) Calcific tendinitis of the rotator cuff: state of the art in diagnosis and treatment. J Orthop Traumatol 17(1): 7-14.

3. Angelo De Carlı, Ferdınando Pulcınellı, Giacomo Delle Rose, Darıo Pıtıno, Andrea Ferrettı (2014) Calcific tendinitis of the shoulder. Joints 2(3): 130-136.

4. Nathalie J Bureau (2013) Calcific tendinopathy of the shoulder. Semin Musculoskelet Radio 17(1): 80-84.

5. Ioppolo F, Tattoli M, Di Sante L, Venditto T, Tognolo L, et al. (2013) Clinical improvement and resorption of calcifications in calcific tendinitis of the shoulder after shock wave therapy at 6 months' follow-up: a systematic review and meta-analysis. Arch Phys Med Rehabil 94(9): 1699-1706.

6. Francesco Oliva, Alessio Giai Via and Nicola Maffulli (2012) Physiopathology of intratendinous calcific deposition. BMC Med 10: 95.

7. Uhthoff HK, Loehr JW (1997) Calcific Tendinopathy of the Rotator Cuff: Pathogenesis, Diagnosis, and Management. J Am Acad Orthop Surg 5(4): 183-191.

8. Scibek JS, Carcia CR (2012) Presentation and conservative management of acute calcific tendinopathy: a case study and literature review. J Sport Rehabil 21(4): 334-342.

9. Kam-Lung T, Siu-Bon W (2015) Arthroscopic debridement for bilateral calcific tendinitis of the subscapularis Tendons : a case report . Journal of Orthopaedic Surgery 23(1): 116-119. 